\title{
Tributos locales
}

\author{
Domingo Jesús JiméneZ-VALLAdOLID De L’HotelleRIe-FalLois \\ Profesor Contratado Doctor de Derecho Financiero y Tributario \\ Universidad Autónoma de Madrid \\ César MARTínEZ SÁNCHEZ \\ Profesor Contratado Doctor de Derecho Financiero y Tributario \\ Universidad Autónoma de Madrid \\ Neus TEIXIDOR MARTÍNEZ \\ Abogada e Investigadora en formación \\ Universidad Autónoma de Madrid
}

\begin{abstract}
Palabras clave: haciendas locales; impuestos locales; impuesto sobre bienes inmuebles.
\end{abstract}

Keywords: local finance; local taxes; property tax.

SUMARIO: I. INTRODUCCIÓN.-II. PRINCIPIOS DE ORDENACIÓN DE LAS HACIENDAS LOCALES.-III. INGRESOS DE LAS HACIENDAS LOCALES: 1. Ingresos tributarios: 1.1. Impuestos: 1.1.1. Impuesto sobre Bienes Inmuebles. 1.1.2. Impuesto sobre Actividades Económicas. 1.1.3. Impuesto sobre Vehículos de Tracción Mecánica. 1.1.4. Impuesto sobre Construcciones, Instalaciones y Obras. 1.1.5. Impuesto sobre el Incremento del Valor de los Terrenos de Naturaleza Urbana. 1.2. Tasas: 1.2.1. Tasas por la utilización privativa o el aprovechamiento especial del dominio público. 1.2.2. Tasas por la prestación de servicios o realización de actividades públicas. 1.3. Contribuciones especiales. 2. Otros ingresos.-IV. PROCEDIMIENTOS TRIBUTARIOS EN EL ÁMBITO LOCAL.

\section{INTRODUCCIÓN}

El 2020 ha sido un año de parálisis normativa en términos generales para las haciendas locales como consecuencia de la crisis sanitaria creada por la covid-19. Sin perjuicio de ello, nuestros tribunales y, especialmente, nuestro Tribunal Supremo, han tenido la oportunidad de pronunciarse en 2020 sobre múltiples aspectos en relación con los ingresos de las haciendas locales que revisten un gran interés. En este ámbito destaca la 
sentencia del Tribunal Supremo de 18 de mayo de 2020 sobre el alcance de la declaración de nulidad de valores catastrales en el marco del Impuesto sobre Bienes Inmuebles. Junto a ella, otros pronunciamientos de relevancia del Tribunal Supremo se han producido en el ámbito del Impuesto sobre el Incremento de Valor de los Terrenos de Naturaleza Urbana, el Impuesto sobre Construcciones, Instalaciones y Obras o las tasas locales. Junto a estos pronunciamientos destaca la labor de la doctrina que, durante 2020, ha dado a luz un buen número de trabajos de interés que analizan tanto nuestra normativa y su interpretación por los tribunales de justicia, como propuestas de lege ferenda que pueden servir para futuras modificaciones de los tributos locales.

\section{PRINCIPIOS DE ORDENACIÓN DE LAS HACIENDAS LOCALES}

En relación con los principios de ordenación de las haciendas locales, debemos comenzar reseñando una sentencia de nuestro Tribunal Constitucional (TC) que, si bien se refiere a la financiación de las diputaciones provinciales, contiene algunas reflexiones acerca del principio de suficiencia financiera local que pueden ser relevantes para los distintos entes locales. Se trata de la Sentencia 82/2020, de 15 de julio. En esta sentencia, el TC analiza la constitucionalidad de la Ley 3/2019, de 18 de febrero, de servicios sociales inclusivos de la Comunidad Valenciana en relación con la autonomía provincial y, particularmente, con el principio de suficiencia financiera local recogido en el art. 142 de la Constitución. Sin perjuicio de otros aspectos que se desarrollan en la sentencia, es de relevancia el papel de garante de la suficiencia local que deben tener las Comunidades Autónomas en aquellos casos en que se atribuya a los entes locales de nuevas competencias por la normativa autonómica o se amplíen estas competencias. De este modo, se extiende la correlación entre la atribución de competencias a los entes locales y la salvaguarda de la suficiencia financiera para su ejecución también al nivel autonómico.

Por otro lado, como viene siendo habitual, nuestros tribunales han tenido que examinar el posible solapamiento de algunos impuestos autonómicos con los tributos locales. En concreto, en 2020 el Tribunal Supremo (TS) ha examinado el solapamiento del Impuesto valenciano sobre Actividades que inciden en el Medio Ambiente y el Impuesto sobre Actividades Económicas (IAE) en sus sentencias de 15 de octubre de 2020 (ECLI:ES:TS:2020:3289) y de 11 de noviembre de 2020 (ECLI:ES:TS:2020:3775). En estas sentencias se plantea la posible vulneración del art. 6.3 de la Ley Orgánica 8/1980, de 22 de septiembre, de Financiación de las Comunidades Autónomas (LOFCA), por la normativa autonómica. El Tribunal Supremo, a la luz de las similitudes entre el impuesto valenciano y el Impuesto murciano sobre Instalaciones que incidan en el Medio Ambiente cuyo hecho imponible el Tribunal Constitucional considero que no coincidía con el del IAE en su STC 22/2019 (vid. Anuario 2019, p. 314), excluye que pueda considerarse la existencia de una vulneración del principio de prohibición de la doble imposición entre el impuesto en cuestión y el IAE. 
Por último, en lo que respecta a los trabajos doctrinales publicados sobre la materia en 2020, cumple destacar los trabajos de G. MENÉndez GARCíA, «Análisis de los beneficios fiscales que podrían establecerse en los Impuestos Municipales por medio de Ordenanzas para hacer frente a la crisis generada por la covid-19", Tributos Locales, núm. 144, 2020, pp. 73-80, y de Á. SANTODOMINGO GONZÁLEZ, «La financiación tributaria local española. Una perspectiva comparada», Carta Tributaria, núm. 55, 2019.

\section{INGRESOS DE LAS HACIENDAS LOCALES}

\section{Ingresos tributarios}

\subsection{Impuestos}

\subsubsection{Impuesto sobre Bienes Inmuebles}

Durante el ejercicio 2020 no se han producido modificaciones legislativas relevantes en el ámbito del Impuesto sobre Bienes Inmuebles (IBI). Para dicho ejercicio, como ya expusimos en el Anuario de Derecho Municipal 2019 (p. 309), el art. 6 del Real Decretoley 18/2019, de 27 de diciembre, por el que se adoptan determinadas medidas en materia tributaria, catastral y de seguridad social, establece unos coeficientes de actualización de los valores catastrales de acuerdo con el procedimiento previsto en el art. 32.2 del Real Decreto Legislativo 1/2004, de 5 de marzo, por el que se aprueba el Texto Refundido de la Ley del Catastro Inmobiliario (TRLCI). Se trata de diferentes coeficientes aplicados en función del año de entrada en vigor de los valores catastrales aprobados mediante un procedimiento de valoración colectiva y que se aplican a los municipios recogidos en la Orden HAC/1257/2019, de 17 de diciembre, por la que se establece la relación de municipios a los que resultarán de aplicación los coeficientes de actualización de los valores catastrales que establezca la Ley de Presupuestos Generales del Estado para el año 2020. A este respecto, debemos destacar que, para el ejercicio 2021, pese a que se aprobó la Ley 11/2020, de 30 de diciembre, de Presupuestos Generales del Estado para el año 2021, la misma no prevé la aplicación de dichos coeficientes de actualización.

Como ya mencionamos en el Anuario de Derecho Municipal 2019 (p. 310), el art. 4 del Real Decreto-ley 7/2019, de 1 de marzo, de medidas urgentes en materia de vivienda y alquiler, convalidado mediante Resolución del Congreso de los Diputados de 3 de abril de 2019, modificó parcialmente el Real Decreto Legislativo 2/2004, de 5 de marzo, por el que se aprueba el Texto Refundido de la Ley Reguladora de las Haciendas Locales (TRLRHL), introduciendo el concepto de bien inmueble de uso residencial desocupado con carácter permanente. Esta reforma ha sido analizada por algunos autores como J. E. Varona Alabern (ed. lit.), La fiscalidad de la vivienda desocupada, Aranzadi Thomson Reuters, 2020; J. E. VARONA ALABERN, «El sedicente recargo del IBI sobre las viviendas desocupadas con carácter permanente», Quincena fiscal, núm. 18, 2020, pp. 17-54; 
J. M. Guasch Muñoz, «El recargo sobre el impuesto sobre bienes inmuebles de las viviendas desocupadas. Análisis práctico", El Consultor de los Ayuntamientos y de los Juzgados, núm. extra 4, 2020, pp. 115-130; J. CALVO VÉRGEZ, «A vueltas con la aplicación de un recargo en el IBI sobre las viviendas vacías a la luz de la reciente jurisprudencia constitucional», Gaceta fiscal, núm. 404, 2020, pp. 87-119; R. PALA, «Las ordenanzas municipales ante el recargo en el IBI sobre viviendas desocupadas", Actualidad jurídica Aranzadi, núm. 960, 2020, p. 8; y A. NAVARRO GARCíA, «¿Es por fin aplicable el recargo sobre inmuebles de uso residencial desocupados en el IBI?», en E. MARÍA CORDERO GONZÁlez y J. GARCía PUENTE (coord.), Reformas recientes y pendientes del sistema tributario español, 2020, pp. 273-291.

Una sentencia especialmente relevante en el año 2020, ha sido la STS de 18 de mayo de 2020 (ECLI:ES:TS:2020:966), que se plantea el alcance de la declaración de nulidad de los valores catastrales. En ese sentido, concluye que las liquidaciones del IBI que utilizan dicho valor como base imponible, pese a ser emitidas con posterioridad, también deben reputarse nulas, pues el Ayuntamiento no puede mantener su validez escudándose en la existencia de la dualidad de gestión. Esta sentencia ha sido objeto de análisis en D. MARÍN-BARNUEVO FABO, «Procede la anulación inmediata de las liquidaciones del IBI cuando se anula la valoración catastral: análisis de la STS de 18 de mayo de 2020, rec. núm. 6950/2018", Estudios financieros, Revista de contabilidad y tributación, núm. 451, 2020, pp. 135-144; Ó. DEL AMO GALÁN, «Ponencia de valores y liquidación del IBI (Sentencia del Tribunal Supremo no. 444/2020, de 18 de mayo)", Carta tributaria, núm. 65-66, 2020; y B. SESMA SÁNCHEZ, «La invalidez sobrevenida del IBI: causas y alternativas de revisión", Quincena fiscal, núm. 1-2, 2020, pp. 17-42.

Asimismo, resulta de interés la STS de 18 de mayo de 2020 (ECLI:ES:TS:2020:971), que concluye que no procede anular una liquidación del IBI alegando defectos en la ponencia de valores, cuando esa ponencia ha sido impugnada por otros contribuyentes y la Audiencia Nacional ha estimado que es ajustada a derecho, siendo esta sentencia firme. En relación con el tipo de gravamen diferenciado, la sentencia del Tribunal Superior de Justicia (TSJ) de Madrid de 2 de enero de 2020 (ECLI:ES:TSJM:2020:1147) determina que no puede apreciarse su confiscatoriedad con simples alegaciones genéricas o comparaciones. Además, la STSJ de Castilla y León de 17 de junio de 2020 (ECLI:ES:TSJCL:2020:2195) considera innecesario el planteamiento de una cuestión de inconstitucionalidad en relación con la coexistencia del Impuesto sobre el Patrimonio y el IBI, pues, a su entender, no se produce una duplicidad de tributación sobre el mismo hecho imponible.

Por otro lado, un aspecto tratado tanto por la jurisprudencia como por la doctrina son los beneficios fiscales. Una sentencia interesante en esta materia ha sido la STS de 11 de mayo de 2020 (ECLI:ES:TS:2020:986), que concluye que la exención del IBI de los bienes inmuebles afectos a fines propios de las universidades resulta aplicable, pues el art. 80.1 de la Ley Orgánica 6/2001, de 21 de diciembre, de Universidades, no ha sido derogado. Asimismo, la STS de 18 de junio de 2020 (ECLI:ES:TS:2020:1824) considera que la declaración prevista en el art. 62.1.a) del TRLRHL es aplicable a aquellos bienes 
inmuebles propiedad del Estado, de las Comunidades Autónomas o de las entidades locales directamente afectos a servicios educativos, debiéndose interpretar dicha afección de manera restrictiva. Además, la STSJ de Castilla-La Mancha (Albacete) de 10 de febrero de 2020 (ES:TSJCLM:2020:425) ha determinado que las viviendas del funcionariado de la Guardia Civil ubicadas fuera de la Casa Cuartel o Acuartelamiento no pueden considerase exentas de IBI. Así, la Consulta vinculante de la Dirección General de Tributos (DGT) núm. V, 1771/2020, de 3 de junio de 2020, recoge que exención prevista en el art. 62.2.b) del TRLRHL solamente es de aplicación a aquellos inmuebles declarados, de forma expresa e individualizada, monumento o jardín histórico de interés cultural inscritos en el registro general como integrantes del Patrimonio Histórico Español, siempre que no estén afectos a actividades económicas.

Igualmente, diversos autores han publicado trabajos en relación con las exenciones y bonificaciones del IBI. Entre ellos, debemos destacar los trabajos de D. CABEZUELO VALENCIA, «Exención del IBI de un bien histórico de interés cultural arrendado", La administración práctica, núm. 10, 2020, pp. 205-208; J. M. FARFÁn PÉREZ, «Bonificaciones potestativas en el IBI», El Consultor de los Ayuntamientos y de los Juzgados, núm. extra 4, 2020, pp. 102-113; G. ORÓN MORATAL, «Las bonificaciones obligatorias y una potestativa en el Impuesto sobre Bienes Inmuebles», El Consultor de los Ayuntamientos $y$ de los Juzgados, núm. extra 4, 2020, pp. 92-101; J. I. GOMAR SÁNCHEZ, «Exenciones de oficio en el Impuesto de Bienes Inmuebles», El Consultor de los Ayuntamientos y de los Juzgados,núm. extra 4, 2020, pp. 62-75; F. J. MAGRANER MORENO, «Las exenciones rogadas en el IBI», El Consultor de los Ayuntamientos y de los Juzgados, núm. extra 4, 2020, pp. 76-91; y P. CUBILES SÁNCHEZ-POBRE, «Las exenciones aplicables por la Iglesia Católica en el lBI y en el lCIO», Tributos locales, núm. 145, 2020, pp. 33-53.

Durante el ejercicio 2020, el Tribunal Supremo ha admitido a trámite diversos recursos de casación relativos a la regulación del IBI. A este respecto, como se recoge en el Auto del TS (ATS) de 6 de noviembre de 2020 (ECLI:ES:TS:2020:10427A), debe pronunciarse sobre si la suspensión indefinida de la ejecución del planeamiento urbanístico por problemas de inundabilidad permite, de forma equiparable a la nulidad de dicho planeamiento, la impugnación del valor catastral a partir de las liquidaciones del IBI. Asimismo, conforme al ATS de 25 de septiembre de 2020 (ECLI:ES:TS:2020:7742A), deberá determinar si el acceso a información relativa a los bienes inmuebles exentos de pago del IBI constituye o no un régimen jurídico específico de acceso a la información. Además, el ATS de 22 de octubre de 2020 (ECLI:ES:TS:2020:9431A) plantea si el procedimiento de regularización catastral constituye o no una causa de interrupción de la prescripción del Derecho de la Administración a liquidar el IBI. De hecho, en relación con la prescripción del IBI debemos destacar el trabajo de M. C. GÓMEZ DE LA TORRE ROCA, «Interrupción de la prescripción del derecho a liquidar el IBI», El Consultor de los Ayuntamientos y de los Juzgados, núm. extra 4, 2020, pp. 50-61.

Finalmente, debemos destacar diversos trabajos doctrinales publicados a lo largo del ejercicio 2020 en relación con este impuesto. Nos referimos a J. RodRíGUEZ MÁr- 
QUEZ. «Impuesto sobre bienes inmuebles», en P. J. CARRASCO PARRILla (dir.), Derecho tributario local y procedimientos tributarios, 2020, pp. 153-196; B. MORENO SERRANO, «Infografías sobre el IBI», El Consultor de los Ayuntamientos y de los Juzgados, núm. extra 4, 2020, pp. 19-22; D. MARÍn-BARNUEVO FABO, «2. El Impuesto sobre Bienes Inmuebles», en D. MARÍN-BARNueVo FABO (dir.), La tributación local en esquemas, 2020, pp. 37-66; R. R. SOLER BELDA, «La propiedad ante los impuestos locales de exigencia obligatoria: el impuesto sobre bienes inmuebles», en C. M. LÓPEZ ESPADAFOR (coord.), Dimensión fiscal del derecho de propiedad, 2020, pp. 243-276; y J. SuÁrEZ PANDIELlo, «Repensando el IBI», El Consultor de los Ayuntamientos y de los Juzgados, núm. extra 4, 2020, pp. 156-167.

\subsubsection{Impuesto sobre Actividades Económicas}

En el ámbito del Impuesto sobre Actividades Económicas (IAE) debemos comenzar señalando la modificación del Real Decreto Legislativo 1175/1990, de 28 de septiembre, por el que se aprueban las Tarifas y la Instrucción del Impuesto sobre Actividades Económicas a través del art. 67 de la Ley 11/2020, de 30 de diciembre, de Presupuestos Generales del Estado para el año 2021 (LPGE 2021). De acuerdo con la Exposición de motivos de la LPGE 2021, la modificación tiene las siguientes implicaciones: «Se crean nuevos epígrafes o grupos en las Tarifas del (IAE), con el fin de clasificar de forma específica las actividades de comercialización de los suministros de carácter general (electricidad y gas), que hasta la fecha carecen de dicha clasificación, se crea un epígrafe para las grandes superficies comerciales que no se dedican principalmente a la ropa o a la alimentación y que hasta ahora carecían de epígrafe propio, de suerte que se les da un tratamiento similar a los demás centros comerciales, dentro del Grupo 661, "Comercio mixto integrado o en grandes superficies" y se crea un epígrafe para la nueva actividad de suministro de energía a vehículos eléctricos a través de puntos de recarga instalados en cualquier lugar, ya sea en la vía pública, gasolineras, garajes públicos y privados o en cualquier otro emplazamiento». Junto a esta modificación, son relevantes para el IAE las declaraciones como acontecimientos de excepcional interés público a los efectos del art. 27 de la Ley 49/2002 de distintos acontecimientos incluidos en las disposiciones adicionales sexagésima séptima a nonagésima séptima de la LPGE 2021.

Desde el punto de vista de la gestión del impuesto, también deben reseñarse las $O r$ denes HAC/1282/2020, de 28 de diciembre, sobre delegación de la gestión censal del Impuesto sobre Actividades Económicas; y HAC/1281/2020, de 28 de diciembre, sobre delegación de la inspección del Impuesto sobre Actividades Económicas, así como la Resolución de 18 de mayo de 2020, del Departamento de Recaudación de la Agencia Estatal de Administración Tributaria, por la que se modifica el plazo de ingreso en periodo voluntario de los recibos del Impuesto sobre Actividades Económicas del ejercicio 2020 relativos a las cuotas nacionales y provinciales, y se establece el lugar de pago de dichas cuotas. 
En relación con la actividad de nuestros tribunales, debemos destacar, en primer lugar, diversas sentencias dictadas por nuestro TS en relación con el IAE. En primer lugar, en la STS de 21 de mayo de 2020 (ECLI:ES:TS:2020:1422), aclara las diferencias entre las descripciones de los epígrafes 674.4 (supermercados) y 661.3 (almacén popular). En la STS de 9 de julio de 2020 (ECLI:ES:TS:2020:2352), el TS determina que el epígrafe correspondiente en el IAE para empresas que desarrollan actividades consistentes en la promoción de los productos y servicios bancarios y financieros de un banco conforme a un acuerdo contractual, sin que constituya su objeto la actividad financiera o bancaria, es el 831.9 (otros servicios financieros). Para el TS a la hora de determinar si el epígrafe aplicable es el citado 831.9 o el 849.9 (otros servicios independientes) es elemento relevante es la naturaleza del servicio instado. Por último, en la STS de 3 de diciembre de 2020 (ECLI:ES:TS:2020:4030), el TS confirma que «la facultad de liquidar el IAE [...] comprende la posibilidad de modificar de oficio la matrícula del IAE cuando se constate, en el ejercicio de la función de inspección que tiene delegada por la Administración estatal, que el contribuyente no se encuentra correctamente encuadrado en el epígrafe que le corresponde».

Nuestros tribunales inferiores se han pronunciado en un buen número de pronunciamiento acerca de aspectos controvertidos de este impuesto, de los cuales conviene destacar, en primer lugar, la Sentencia de la Audiencia Nacional $(A N)$ de 22 de junio de 2020 (ECLI:ES:AN:2020:1577), en que se descarta que el gravamen en el IAE de las empresas prestadoras de servicios de comunicaciones electrónicas pueda ser incompatible con la Directiva 2002/20/CE del Parlamento Europeo y del Consejo de 7 de marzo de 2002, relativa a la autorización de redes y servicios de comunicaciones electrónicas. Junto a la anterior, también merece ser reseñada la STSJ de Extremadura de 5 de noviembre (ECLI:ES:TSJEXT:2020:921), en que se aclara que las actividades realizadas por las empresas comercializadoras de energía eléctrica a través de las redes de distribución se realizan en los términos municipales cuyo vuelo, suelo o subsuelo se ocupa por las respectivas redes de suministro.

Por último, durante 2020 también se han publicado diversos trabajos académicos de interés en materia de IAE: J. Á. GÓMEZ REQUENA, «El impuesto sobre actividades económicas", en P. CARRASCO PARRILla (dir.), Derecho tributario local y procedimientos tributarios, Atelier, 2020, pp. 197-227; B. SESMA SÁNCHEZ, "El Impuesto sobre Actividades Económicas», en D. MARín-BARNUEVO FABO (dir.), La tributación local en esquemas, IDL-UAM, 2020, pp. 67-82; P. HERRERA MOLINA, «Bonificaciones y otros elementos ambientales en el Impuesto sobre Actividades Económicas (situación actual y propuestas de reforma)», Nueva Fiscalidad, núm. 3, 2020, pp. 21-51; J. Calvo VérGEZ, "La aplicación del IAE en los grupos de empresas», Revista de Estudios Locales. CUNAL, núm. 234, 2020, pp. 16-41; Ó DEL AMO GALÁN, «Potencia instalada como elemento tributario del Impuesto sobre Actividades Económicas», Carta Tributaria, núm. 63, 2020; o D. CABezuelo Valencia, «Exposición pública de la matrícula del Impuesto sobre Actividades Económicas», La Administración práctica, núm. 11, 2020, pp. 193-198. 


\subsubsection{Impuesto sobre Vehículos de Tracción Mecánica}

Al igual que en años anteriores, no se ha producido ninguna modificación en la regulación básica del Impuesto sobre Vehículos de Tracción Mecánica (IVTM). Del mismo modo, la actividad de nuestros tribunales en relación con este impuesto no ha sido reseñable en este 2020. Sin perjuicio de ello, sí debe ser objeto de mención la actividad de la Dirección General de Tributos, que ha resuelto dos consultas vinculantes de notable interés.

En la primera de ellas, de 6 de abril de 2020 (V0713-20), la Subdirección General de Tributos Locales de la Dirección General de Tributos analiza la aplicación de la exención prevista en el art. 93.1.f) del TRLRHL a una entidad que presta el servicio de transporte público de estudiantes con necesidades especiales y transporte adaptado para personas dependientes. A estos efectos, considera la Subdirección General de Tributos Locales que no puede hacerse depender la aplicación de la exención «a que el servicio se preste mediante gestión directa o indirecta o mediante una empresa, ni a que el transporte se realice como servicio regular o discrecional», sino que debe acreditarse la adscripción de los vehículos al transporte público urbano y que tienen un número de plazas, incluyendo la del conductor, superior a nueve. Aunque se cumplan tales requisitos, la exención no procedería en los casos en que el transporte fuera interurbano.

La segunda consulta, de 23 de abril de 2020 (V1016-20), fue examinada por la Subdirección General de Impuestos Especiales y de Tributos sobre el Comercio Exterior de la Dirección General de Tributos. En esta consulta se planteaba por parte de una persona con una discapacidad superior al 33 por 100 la adquisición de un vehículo para los desplazamientos de su hermano, del cual era tutor y conviviente, el cual tenía movilidad reducida y una discapacidad superior al 75 por 100. El consultante planteaba, entre otras cuestiones, si podría beneficiarse de la exención en el IVTM prevista en el art. 93.1.e) TRLRLHL. La Subdirección General de Impuestos Especiales y de Tributos sobre el Comercio Exterior concluye que lo relevante a efectos de la aplicación de esta exención es el hecho de que el titular del vehículo tenga una discapacidad en grado superior al 33 por 100, sin perjuicio de que no conduzca el vehículo o carezca de permiso de conducir.

En relación con la actividad de la doctrina, debemos comenzar destacando dos trabajos que analizan la STC 87/2019 a la que nos referimos en la edición anterior de este Anuario. Se trata de los trabajos de A. Tandazo Rodríguez; P. Herrera Molina, "Constitucionalidad y comentario crítico del impuesto catalán sobre emisiones de dióxido de carbono de los vehículos de tracción mecánica (Análisis de la STC 87/2019, de 20 de junio, rec. núm. 5334/2017)», Estudios financieros. Revista de contabilidad y tributación, núm. 442, 2020, y J. CALVO VÉRGEZ, «El impuesto catalán sobre emisiones de dióxido de carbono de los vehículos de tracción mecánica y su declaración de constitucionalidad», en C. GarCía-Herrera Blanco (dir.), VIII Encuentro de Derecho Financiero y Tributario: La fiscalidad en el marco de la transición ecológica, Documentos. Instituto de Estudios Fiscales, núm. 6, 2020, pp. 9-21. Deben destacarse también en relación con 
el IVTM los trabajos de P. CHICO DE LA CÁMARA, «El impuesto sobre vehículos de tracción mecánica», en P. CARRASCO PARRILla (dir.), Derecho tributario local y procedimientos tributarios, Atelier, 2020, pp. 229-282; C. MARTíneZ SÁNCHEZ, «Impuesto sobre Vehículos de Tracción Mecánica», en D. MARíN-BARNUEVO FABO (dir.), La tributación local en esquemas, IDL-UAM, 2020, pp. 83-96; y Ó. DEL AMO GALÁN, «Bonificación en el impuesto sobre vehículos de tracción mecánica para vehículos históricos y antiguos», Carta Tributaria, núm. 67, 2020.

\subsubsection{Impuesto sobre Construcciones, Instalaciones y Obras}

$\mathrm{Al}$ igual que en el caso del IVTM, no ha tenido lugar ninguna modificación en la regulación del Impuesto sobre Construcciones, Instalaciones y Obras (ICIO) durante 2020. Sin perjuicio de ello, durante este año debe destacarse la intensa actividad de nuestro TS en relación con este impuesto.

En primer lugar, se han de reseñar varias SSTS en que se confirma la vigencia de la exención prevista en el art. 80.1 de la Ley Orgánica/2001, de Universidades, sin que se pueda entender que esta previsión fuera derogada por la Ley 51/2002 de modo similar a como ha acontecido en la referida STS de 11 de mayo de 2020 en el marco del IBI. De este modo, las construcciones, instalaciones y obras en o de bienes inmuebles afectos a los fines de las universidades se encuentran cubiertos por la citada exención. Así lo confirma el TS en las sentencias de 19 de mayo de 2020 (ECLI:ES:TS:2020:1120) y de 17 de diciembre de 2020 (ECLI:ES:TS:2020:4315). Junto a ello, otro grupo de sentencias del TS vienen a examinar cuándo ha de entenderse que comienza el cómputo del plazo de prescripción para la solicitud de la devolución de ingresos indebidos en los casos en que las obras no son ejecutadas por desistimiento del solicitante. El TS ha determinado que «es necesario que exista un acto expreso de desistimiento o renuncia por el solicitante de la licencia de obras, o un acto formal de declaración de la caducidad de la licencia por parte del Ayuntamiento, pues tales actos suponen la constancia de que la obra no se va a ejecutar y que, por tanto, no se va a realizar el hecho imponible del citado impuesto». En este sentido se ha pronunciado el TS en sus sentencias de 4 de noviembre de 2020 (ECLI:ES:TS:2020:3581) y de 11 de noviembre de 2020 (ECLI:ES:TS:2020:3720). Sobre estos aspectos puede consultarse el trabajo de I. SubERBIOLA GARBIZU, «Seguridad jurídica y dies a quo del cómputo del plazo de prescripción para solicitar la devolución de ingresos indebidos del ICIO. Análisis del ATS 12951/2019, de 12 de diciembre de 2019", Nueva Fiscalidad, núm. 1, 2020, pp. 275-284. Otra sentencia que examina aspectos temporales en relación con la prescripción en el ICIO es la de 22 de junio de 2020 (ECLI:ES:TS:2020:2024), en que se analiza cuándo ha de entenderse que tiene lugar el dies a quo para computar el plazo de prescripción. En esta sentencia el TS afirma que «el dies a quo para computar el plazo de prescripción no parte de la presentación al ayuntamiento del certificado final de obras, sino que finaliza con la ejecución material de la misma, por más que el ayuntamiento lo sepa después». 
Otro grupo de sentencias del TS resuelven recursos de casación planteados por el Canal de Isabel II en relación con la exención prevista en el art. 100.2 TRLRHL. En estas sentencias, el TS señala que para aplicar esta exención «[t]ratándose de las construcciones, instalaciones u obras que se destinen a las obras de infraestructura numerus clausus [...] lo relevante es atender a quién va a ser finalmente el propietario de la obra, en los términos ya expuestos en relación con los bienes demaniales» en aquellos casos en que no coincida la condición de propietario del inmueble y la de dueño de la obra, frente a la posibilidad de tener en cuenta a la persona que soporta los gastos que comporta su realización. Así se ha pronunciado el TS en sus sentencias de 24 de junio de 2020 (ECLI:ES:TS:2020:2220), de 23 de septiembre de 2020 (ECLI:ES:TS:2020:2975) y de 16 de diciembre de 2020 (ECLI:ES:TS:2020:4347).

En las sentencias de 10 de junio de 2020 (ECLI:ES:TS:2020:1667) y de 16 de septiembre de 2020 (ECLI:ES:TS:2020:2891) se analiza si deben excluirse de la base imponible del ICIO las bajas de licitación y de adjudicación correspondiente a la obra ejecutada del coste real y efectivo de la construcción, instalación u obra. El TS entiende que estos conceptos deben excluirse en aplicación del art. 102.1 TRLRHL en tanto que deben «excluirse de la base imponible todos aquellos elementos que no forman parte del coste de ejecución material, y la baja de licitación o de adjudicación en cuanto valor que se deduce del propio presupuesto de ejecución material, resulta ajeno al coste real y efectivo de las obras y debe excluirse de la base imponible del ICIO en la liquidación definitiva, y que en los supuestos, como es el caso, de obras públicas, debe coincidir con lo realmente pagado por la Administración». Estos aspectos, así como otros conexos, han sido objeto de análisis en los trabajos de Á. SANTODOMINGO GONZÁLEZ, «Las bajas de adjudicación y el ICIO», Carta Tributaria, núm. 67, 2020, y D. OrTIZ EsPEjO, «Algunas consideraciones sobre la determinación de la base imponible del ICIO en los contratos de obras adjudicados por el sector público», Tributos Locales, núm. 147, 2020, pp. 87-101; o C. Márquez Sillero, A. MárqueZ y MárqueZ, "Contenido jurídico tributario de los términos legales "coste real y efectivo" equivalente a "ejecución material" de la obra, que constituyen la base imponible del tributo municipal Impuesto sobre construcciones, instalaciones y obras (ICIO)», Quincena fiscal, núm. 4, 2020, pp. 51-60

Otro aspecto que ha dado lugar a controversia y que ha sido objeto de examen por nuestro TS en 2020 ha sido el relativo al empleo de precios publicados oficialmente en bases de datos de colegios profesionales como justificación de la comprobación de valores en el ICIO. El TS en su sentencia de 3 de junio de 2020 (ECLI:ES:TS:2020:1661) ha venido a afirmar que «(i) la Administración puede comprobar el coste real y efectivo de la construcción, instalación u obra en el ICIO acudiendo a alguno de los métodos establecidos en el art. 57.1 de la Ley General Tributaria y (ii) el informe emitido en el caso por arquitecto técnico municipal utilizando los precios publicados oficialmente por el colegio oficial de arquitectos, así como las facturas emitidas en otras licencias de obras por suministradores independientes constituye una auténtica comprobación de valores del apartado e) del art. 57.1 de la Ley General Tributaria». Esta sentencia ha sido analizada en los trabajos de R. FraIle FERNÁNDEZ, «La liquidación definitiva del 
ICIO. Especial atención a los casos en que la liquidación provisional siguió el método de estimación objetiva y al empleo de bases de datos de Colegios Profesionales», Tributos Locales, núm. 144, 2020, pp. 91-110; y «El derecho a tasación pericial contradictoria cuando la Administración valora la base imponible del ICIO atendiendo a los precios medios de los colegios profesionales: análisis de la STS de 3 de junio de 2020, rec. núm. 3067/2017», Estudios financieros. Revista de contabilidad y tributación, núm. 452, 2020, pp. 125-133. Otra STS de interés en el ámbito de la comprobación de valores en el ICIO ha sido la 18 de junio de 2020 (ECLI:ES:TS:2020:1923), en que cuestiona si la comprobación por la Administración tributaria de la base imponible autoliquidada por el sujeto pasivo tras la finalización de la obra constituye una comprobación de valores a los efectos del art. 57 de la Ley 58/2003, General Tributaria (LGT), o si se trata de un supuesto en que la Administración está procediendo a determinar directamente la base imponible a través de la aplicación del método de estimación directa. El TS descarta que la actuación de la Administración deba entenderse directamente como el desarrollo de una comprobación de valores en los siguientes términos: «La Administración puede comprobar el coste real y efectivo de las obras acudiendo a los medios de comprobación previstos en el actual art. 57 de la LGT, pero no está obligada a ello en supuestos, como el presente, en que la comprobación previa a la determinación de la base imponible del impuesto ha consistido en la documentación aportada por la recurrente a requerimiento de la Administración».

Otra STS de interés es la de 19 de noviembre de 2020 (ECLI:ES:TS:2020:3882), en que se examina qué obras de ampliación o modificación de puertos se encuentran excluidas de control preventivo municipal. El TS afirma que «el concepto de obras de ampliación o modificación de puertos incluidas en el art. 58 del texto refundido de la Ley de Puertos del Estado y de la Marina Mercante, calificadas como obras públicas de interés general excluidas de control preventivo municipal por el art. 60 del mismo texto legal, se debe interpretar en un sentido físico, por lo que solo lo serán aquellas realizadas para ganar terreno al mar». En otra STS dictada el mismo 19 de noviembre de 2020 (ECLI:ES:TS:2020:3955) se analiza la figura del sustituto de contribuyente en el marco del ICIO, afirmando que «se puede otorgar la condición de sustituto del contribuyente a quien ejecuta las obras, con independencia de que el dueño de las mismas haya solicitado previamente la licencia de obras o presentado las autoliquidaciones, o se hubiera iniciado con él un procedimiento de aplicación de los tributos». Finalmente, en la sentencia de 11 de junio de 2020 (ECLI:ES:TS:2020:1890) se analiza la posibilidad de que el contenido de un acta de conformidad dictada en una comprobación en el Impuesto sobre Sociedades pueda tener efectos vinculantes para una liquidación del ICIO dictada con anterioridad. El TS descarta estos efectos vinculantes señalando que: «ni las actas con acuerdo ni, en general, las valoraciones a efectos de otros tributos, vinculan a la Administración, salvo que: a) procedan de la misma Administración; $b$ ) aún a efectos de otros tributos y Administraciones, que lo que se esté valorando, física y jurídicamente, sea la misma cosa, a tenor de la regulación legal de cada figura tributaria, y c) que la valoración que se acepta e incorpora esté suficientemente motivada [...] sin perjuicio de 
que, dentro del procedimiento - y no cuando ha finalizado - y como prueba, se pueda invocar la existencia de actos o pactos que pudieran influir en la determinación de elementos esenciales del tributo de que se trate, que podrán ser valorados como elementos probatorios con arreglo a las reglas que determinan su valoración y carga, tanto en vía administrativa como judicial».

Por último, han de destacarse, junto a los anteriores, los siguientes trabajos doctrinales publicados en relación con este impuesto: D. CABEZUELO VALENCIA, «Bonificación en el ICIO por la rehabilitación de un edificio: tratamiento a efectos del IRPF», $L a$ Administración Práctica, núm. 1, 2020, pp. 197-200; M. RUIZ GARIJO, "Controversias inconclusas del $\mathrm{lCIO}$ a partir de los Recursos de Casación admitidos por el Tribunal Supremo», Tributos Locales, núm. 145, 2020, pp. 13-31; M. Alonso GIL, «La comprobación de la liquidación definitiva del ICIO», Tributos Locales, núm. 148, 20202021, pp. 23-49; O. DEL AMO GALÁN, «Tributación local de la instalación de parques eólicos y huertos solares», Carta Tributaria, núm. 62, 2020; C. MarTínez CeBallos, «La base imponible en la liquidación provisional del Impuesto sobre Construcciones, Instalaciones y Obras», La Ley, núm. 9.663, 2020; I. ROVIRA FERRER, «Una propuesta de reformulación en la gestión del lCIO", Tributos Locales, núm. 144, 2020, pp. 81-90; A. Bergas ForteZA, «Sobre la incompatibilidad establecida en el arte 107 TFUE en las exenciones fiscales. Comentarios a la Sentencia del TJUE de 27 de iunio de 2017. Y su aplicación actual», Tributos Locales, núm. 146, 2020, pp. 89-102; Á. FORNIELES GIL, «El impuesto sobre construcciones, instalaciones y obras», en P. CARRASCO PARRILLA (dir.), Derecho tributario local y procedimientos tributarios, Atelier, 2020, pp. 283323; o D. Marín-BARnUeVo FABO, «El Impuesto sobre Construcciones, Instalaciones y Obras», en D. MARíN-BARNUEVO FABO (dir.), La tributación local en esquemas, IDL-UAM, 2020, pp. 97-122.

\subsubsection{Impuesto sobre el Incremento del Valor de los Terrenos de Naturaleza Urbana}

La normativa del Impuesto sobre el Incremento del Valor de los Terrenos de Naturaleza Urbana (IIVTNU) no ha sufrido modificaciones significativas durante el ejercicio 2020. Así, como viene siendo habitual los últimos años, ha seguido teniendo gran relevancia la STC núm. 59/2017 de 11 de mayo de 2017 (cuestión de inconstitucionalidad 4864-2016), que declara la inconstitucionalidad de la regulación estatal del IIVTNU en la medida en la que permite gravar situaciones inexpresivas de capacidad económica por inexistencia de incremento de valor de los terrenos (vid. Anuario de Derecho Municipal 2017, pp. 295 y ss.; Anuario de Derecho Municipal 2018, pp. 341 y ss., y Anuario de Derecho Municipal 2019, pp. 318 y ss.). A título de ejemplo, la STSJ de Madrid de 30 de julio de 2020 (ECLI:ES:TSJM:2020:9249) confirma la anulación de una liquidación del IIVTNU al haberse acreditado la inexistencia de incremento de valor.

Como ya ocurrió en los tres años precedentes, las consecuencias de esa declaración de inconstitucionalidad y la necesidad de proceder a la modificación de la regulación del 
IIVTNU han sido ampliamente estudiadas por la doctrina. En este sentido, podemos ci$\operatorname{tar}$ S. ANíBARRo PÉREZ, «La inseguridad jurídica creada por la inactividad del legislador en el Impuesto sobre el incremento de valor de los terrenos de naturaleza urbana», Crónica tributaria, núm. 174, 2020, pp. 11-34; B. MORENO SERRANO, «Impuesto sobre el incremento de valor de los terrenos de naturaleza urbana: aspectos más relevantes de su régimen jurídico", El Consultor de los Ayuntamientos y de los Juzgados, 2020; I. PALADINI BRACHO, «Interpretación y eficacia de las sentencias del Tribunal Constitucional. El controvertido caso del Impuesto sobre el Incremento del Valor de los Terrenos de Naturaleza Urbana», en A. Pérez Miras (dir.), G. M. Teruel lozano (dir.), E. C. Raffiotta (dir.), y M. PiA IADiCCO (dir.), Setenta años de Constitución Italiana y cuarenta años de Constitución Española, vol. 4, 2020, pp. 211-228; B. MORENO SERRANO, Impuesto sobre el Incremento de Valor de los Terrenos de Naturaleza Urbana. Su necesaria adaptación a los pronunciamientos constitucionales, Wolters Kluwer, Madrid, 2020; F. PLEITE GUADAMILLAS, «La plusvalía, un impuesto que agoniza», Actualidad administrativa, núm. 2, 2020; I. Rubio Pilarte, "Otra vez el impuesto municipal sobre la plusvalía de los terrenos», Forum fiscal: la revista tributaria de Álava, Bizkaia y Gipuzkoa, núm. 260, 2020; J. B. MARTín QUERALT, "El Impuesto municipal sobre Plusvalía tiene anticuerpos», Carta Tributaria, núm. 64, 2020; G. GARCíA CALLE, «A vueltas con el impuesto sobre el incremento de valor de los terrenos de naturaleza urbana", Revista de estudios locales. Cunal, núm. 228, 2020, pp. 34-56; y B. ANGLÈS JUANPERE, "El impuesto sobre el incremento de valor de los terrenos de naturaleza urbana, ¿y a partir de ahora qué?», en E. M. CoRDERO GONZÁLEZ (coord.), y J. GARCÍA PUENTE (coord.), Reformas recientes y pendientes del sistema tributario español, 2020, pp. 241-254.

Como vimos en ediciones anteriores (vid. Anuario de Derecho Municipal 2017, p. 297; Anuario de Derecho Municipal 2018, p. 344, y Anuario de Derecho Municipal 2019, pp. 320 y ss.), la carga de la prueba de la existencia de minusvalía viene siendo una cuestión controvertida. Resulta de interés la STS de 26 de febrero de 2020 (ECLI:ES:TS:2020:1036), que anula y casa la SJC-A de Cartagena de 30 de mayo de 2017 (ECLI:ES:JCA:2017:358), de la que nos ocupamos en el Anuario de Derecho Municipal 2017 (p. 297). Dicha sentencia causó bastante revuelo al considerar que la declaración de inconstitucionalidad parcial de la normativa conllevaba que fuera la Administración la que debiera probar la existencia de incremento de valor, si bien el TS reitera su doctrina y estima que debe ser el obligado tributario el que tiene que probar el decremento de valor, pudiendo, en su caso, la Administración presentar pruebas en contra. Además, respecto de la aportación de un dictamen pericial por la Administración demandada en un procedimiento abreviado, la STS de 26 de noviembre de 2020 (ECLI:ES:TS:2020:4031) ha establecido que puede aportarse en el propio acto de la vista, si bien debe admitirse la posibilidad de otorgar al recurrente plazo para solicitar aclaraciones al perito y efectuar alegaciones en sus conclusiones. La STSJ de Cataluña de 31 de enero de 2020 (ECLI:ES:TSJCAT:2020:353) se pronuncia sobre la aceptación de las escrituras públicas como medio de prueba. Asimismo, la STSJ de Cataluña de 4 de marzo de 2020 (ECLI:ES:TSJCAT:2020:1743) permite aceptar el valor de adjudicación 
(acreditado por el auto de adjudicación, las facturas correspondientes y los informes de tasación) como valor de transmisión. Sin embargo, la STSJ de Cataluña de 4 de marzo de 2020 (ECLI:ES:TSJCAT:2020:1733) ha juzgado que la notoriedad de que no se ha producido ningún aumento de valor de los terrenos en el territorio español desde el año 2008 no constituye medio de prueba suficiente. De forma adicional, la consulta vinculante de la DGT V3485/2020 de 2 de diciembre de 2020 no acepta la presentación de los recibos del IBI como prueba de dicho decremento de valor.

De forma adicional, como ya manifestamos en el Anuario de Derecho Municipal 2019 (pp. 319 y ss.), la STC núm. 126/2019 de 31 de octubre de 2019 (cuestión de inconstitucionalidad 1020/2019) extiende la declaración de inconstitucionalidad de la normativa a aquellos supuestos en los que existe un incremento de valor inferior a la cuota a abonar en concepto de IIVTNU, por ser confiscatorio. En esta línea, se han pronunciado las SSTS de 9 y 14 de diciembre de 2020 (ECLI:ES:TS:2020:4182 y ECLI:ES:TS:2020:4437) y la STSJ de Aragón de 6 de julio de 2020 (ECLI:ES:TSJAR:2020:828). Igualmente, son numerosos los autores que han abordado el tema, como B. MORENO SERRANO, «El IIVTNU es inconstitucional cuando la cuota a pagar es mayor al incremento realmente obtenido", El Consultor de los Ayuntamientos y de los Juzgados, núm. 1, 2020, pp. 4047; M. C. CÁmara Barroso y M. González Aparicio, «El Tribunal Constitucional vuelve a pronunciarse sobre la plusvalía municipal: Es inconstitucional cuando la cuota supera a la ganancia (Análisis de la STC126/2019, de 31 de octubre, cuestión de inconstitucionalidad 1020-2019)", Estudios financieros. Revista de contabilidad y tributación, núm. 444, 2020; y Ó. DEL AMO GALÁN, «Sentencia del Tribunal Constitucional de 31 de octubre de 2019 en relación con el Impuesto sobre el Incremento de Valor de los Terrenos de Naturaleza Urbana», Carta tributaria, núm. 58, 2020.

Una sentencia que ha tenido especial relevancia en el ejercicio 2020 ha sido la STS de 10 de noviembre de 2020 (ECLI:ES:TS:2020:3724) que ha dilucidado que, a efectos de justificar la inexistencia de incremento de valor del terreno transmitido, no procede la actualización del valor de adquisición del terreno mediante la aplicación del IPC. En el plano doctrina, debemos destacar el trabajo de B. MORENO SERRANO, "iActualización del valor inicial en el IIVTNU?», El Consultor de los Ayuntamientos y de los Juzgados, núm. 11, 2020.

Otra temática relevante este ejercicio 2020 ha sido la incidencia de la forma de transmisión del inmueble en el IIVTNU. Las STSJ de Madrid de 30 de junio de 2020 (ECLI:ES:TSJM:2020:8716) y STSJ de Cataluña de 30 de septiembre de 2020 (ECLI:ES:TSJCAT:2020:6463) analizan supuestos de transmisiones mediante expropiación forzosa. Así, la STSJ de la Región de Murcia de 16 de septiembre de 2020 (ECLI:ES:TSJMU:2020:1815) determina que la aportación de inmuebles a una sociedad se encuentra sujeta al IIVTNU, con independencia de su inscripción en el Registro de la Propiedad. Además, la STS de 18 de mayo de 2020 (ECLI:ES:TS:2020:1028) casa y anula una sentencia que consideró que el beneficio contable declarado en el Impuesto sobre Sociedades podía utilizarse como método de cálculo de la base impo- 
nible. Asimismo, la STS de 26 de febrero de 2020 (ECLI:ES:TS:2020:1030) no admite la posibilidad de utilizar un método de cálculo de la base imponible que difiera del método establecido legalmente. En el plano doctrinal, debemos destacar los trabajos de J. LÓPEZ LEÓN, «Tratamiento en el IlVTNU de la aportación de rama de actividad de personas físicas. Requisitos. Comprobación inspectora», Tributos locales, núm. 145, 2020, pp. 55-69; J. DÍAZ CADÓRNIGA, «Fiscalidad integral en las aportaciones de inmuebles a sociedades de capital: IRPF, IVA, IIVTNU, IRNR, IS, ITP, IAJD, IOS, IDON", Revista Jurídica del Notariado, núm. 110, 2020, pp. 559-620; y D. CABEZUELO VALENCIA, "Tributación de la propiedad compartida en el impuesto sobre el incremento de valor de los terrenos de naturaleza urbana», La administración práctica, núm. 4, 2020, pp. 187-190.

En relación con las operaciones de arrendamiento financiero o leasing, las SSTSJ de Cataluña de 15 y 22 de junio de 2020 (ECLI:ES:TSJCAT:2020:2478 y ECLI:ES:TSJCAT: 2020:3671) entienden que la carga financiera no puede computar a la hora de determinar la existencia de incremento de valor del suelo. Si bien las STSJ de Cataluña de 29 de octubre de 2020 (ECLI:ES:TSJCAT:2020:7970) y STSJ de Madrid de 30 de junio de 2020 (ECLI:ES:TSJM:2020:8717) han matizado que, a estos efectos, no pueden tenerse en cuenta única y exclusivamente el valor de adquisición del bien inmueble por el banco y el valor del ejercicio de la opción de compra por parte del arrendatario financiero, siendo necesaria la aportación de otras pruebas.

Además, no debemos olvidar algunas controversias que se han planteado este año y de las que deberá conocer el Tribunal Supremo. De hecho, el TS deberá determinar si la transmisión mediante arrendamiento financiero produce o no el hecho imponible del IIVTNU (ATS de 28 de mayo de 2020, ECLI:ES:TS:2020:3317A). Por su parte, el ATS de 24 de septiembre de 2020 (ECLI:ES:TS:2020:7761A) plantea la posibilidad de que el titular del derecho de arrendamiento financiero pueda acreditar la realización de obras de conservación en el inmueble a efectos de la exención de dicha transmisión. El ATS de 16 de enero de 2020 (ECLI:ES:TS:2020:251A) plantea si es posible instar la rectificación de una autoliquidación del IIVTNU en base a motivos diferentes a los que se produjo la primera rectificación de la misma. Además, el ATS de 31 de enero de 2020 (ECLI:ES:TS:2020:752A) cuestiona qué método de individualización del valor del terreno debe utilizarse cuando la escritura de adquisición se refiere al valor total del inmueble $y$, por tanto, no individualiza el valor del terreno.

La STS de 22 de septiembre de 2020 (ECLI:ES:TS:2020:2914) desestima una reclamación de responsabilidad del Estado legislador por la declaración de inconstitucionalidad de la normativa del impuesto. Respecto de este tema, podemos citar los trabajos de G. EsCOBAR RocA, «Efectos de la inconstitucionalidad del impuesto de plusvalía municipal: Sentencia del Tribunal Supremo de 22.09.2020", Revista de responsabilidad civil, circulación y seguro, núm. 1, 2021, pp. 39-40; V. A. GARCía MORENO, «Responsabilidad patrimonial del Estado legislador. Una solución para muy pocos contribuyentes que recurrieron y no vieron satisfecha su pretensión: Sentencia del Tribunal Supremo 
núm. 1.682/2019 de 5 diciembre, recurso 59/2019», Carta tributaria, núm. 59, 2020; Ó. DEL AMO GALÁN, «Reclamación de responsabilidad patrimonial del estado legislador en el Impuesto sobre el Incremento de Valor de los Terrenos de Naturaleza Urbana», Carta tributaria, núm. 61, 2020; y J. CALVO VéRGEZ, «La declaración de responsabilidad patrimonial del estado legislador por vulneración del ordenamiento constitucional y el IIVTNU», BIT plus, núm. 248, 2020, pp. 6-22.

Por último, hay que tenerse en cuenta otras aportaciones doctrinales. En concreto, un tema bastante recurrente ha sido la prescripción del IIVTNU del que se han pronunciado I. ARISTEGUI ANDUIZA, «La autoliquidación de la plusvalía municipal y la prescripción del derecho a exigir su pago", El Consultor de los Ayuntamientos y de los Juzgados, núm. 3, 2020, pp. 38-49, y Ó. DEL AMO GALÁN, «Efectos de las comunicaciones de los notarios sobre la prescripción del Impuesto sobre el Incremento de Valor de los Terrenos de Naturaleza Urbana», Carta tributaria, núm. 59, 2020. Además, deben citarse los trabajos de P. J. CARRASCO PARRILLA, «El impuesto sobre el incremento de valor de los terrenos de naturaleza urbana», en P. J. CARRASCO PARRILla (dir.), Derecho tributario local y procedimientos tributarios, 2020, pp. 325-364; D. MARÍN-BARNUEVO FABO, «6. El Impuesto sobre el Incremento de Valor de los Terrenos de Naturaleza Urbana», en D. Marín-Barnuevo Fabo (dir.), La tributación local en esquemas, 2020, pp. 123150; G. PÉrez Chocano, «Fiscalidad en el sector de la construcción: análisis de los principales tributos locales», Diario La Ley, núm. 9733, 2020; D. García Guerrero, «La problemática fiscal de la propiedad en el ámbito local ante los impuestos de aplicación facultativa: el impuesto sobre el incremento del valor de los terrenos de naturaleza urbana», en C. M. LÓPEZ ESPADAFOR (coord.), Dimensión fiscal del derecho de propiedad, 2020, pp. 217-242; I. GÓMEZ AgUiRRE, «Régimen fiscal en la transmisión de inmuebles», Inmueble: Revista del sector inmobiliario, núm. 205, 2020, pp. 30-34; e I. SUBERBIOLA GARBIZU, «De nuevo, sobre la (im)posibilidad de revisar el valor catastral a través del recurso contra la liquidación del IIVTNU. Análisis de la STSJPV 3818/2019, de 30 de diciembre», Nueva fiscalidad, núm. 2, 2020, pp. 263-272.

\subsection{Tasas}

En 2020, el Tribunal Supremo ha dictado aproximadamente 25 sentencias en el ámbito de las tasas locales. A continuación se reseñan las más relevantes.

1.2.1. Tasas por la utilización privativa o el aprovechamiento especial del dominio público

En lo que se refiere a este tipo de tributos, en primer lugar, se ha de citar la STS de 24 de junio de 2020 (ECLI:ES:TS:2020:2212), en la que se resolvió el recurso de casación preparado por el Ayuntamiento de Móstoles (Madrid) contra la sentencia dictada en instancia por el Juzgado de lo Contencioso-Administrativo de Madrid, en la que se es- 
timó el recurso presentado por una mercantil contra diversas liquidaciones por cánones relativos a aparcamientos de residentes.

Por su parte, el TS admitió el recurso, precisando que existían dos cuestiones que presentaban interés casacional objetivo para la formación de jurisprudencia: por un lado, determinar cuál es el plazo de prescripción que resulta aplicable a la obligación de pago del canon municipal exigido por la concesión administrativa para la explotación de un aparcamiento subterráneo para residentes; $y$, por otro lado, aclarar en quién recae la condición de sujeto pasivo del citado canon concesional. En cuanto a esto último, se trataba de dilucidar si lo es la comunidad de usuarios, aun cuando no se le haya atribuido al cesionario obligaciones de conservación y mantenimiento durante toda la duración de la concesión.

Respecto de lo primero, la Sala recuerda que ya su jurisprudencia había calificado un canon idéntico como ingreso tributario. En esta ocasión, reafirma su criterio afirmando que se trata de una tasa por uso privativo del dominio público, con lo que su plazo de prescripción ha de ser el común de los tributos: cuatro años, de acuerdo con lo dispuesto en el art. 66 LGT. Esto implicaba la prescripción de los derechos a liquidar los referidos cánones.

Respecto de la segunda cuestión, el fondo del asunto estribaba en determinar si en la concesión administrativa era condición indispensable para la efectividad de su transmisión la autorización formal por el ayuntamiento, o solamente se requería la correspondiente constitución de la comunidad de usuarios indicada. La Sala concluye que no debe ser considerada como condición necesaria para la eficacia de la transmisión de la concesión especial la posterior autorización del ayuntamiento, «que no haría sino ratificar formalmente lo que ya previamente había establecido el propio ayuntamiento en el pliego de condiciones en el cual queda patente su intención de transmitir la concesión administrativa de los aparcamientos para residentes a las correspondientes comunidades de usuarios» (FD 3. ${ }^{\circ}$ ). Por tanto, es la comunidad de usuarios la que debe ser considerada como sujeto pasivo del referido canon.

En consecuencia, se declaró no haber lugar al recurso interpuesto por la citada entidad local, sin imposición de costas relativas a la casación.

De igual modo, se ha de reseñar la STS de 21 de octubre de 2020 (ECLI:ES:TS:2020: 3400), en la que se resolvió el recurso de casación preparado por el Ayuntamiento de Madrid (Madrid) contra la sentencia dictada en instancia por el Tribunal Superior de Justicia de Madrid, en la que se estimó el recurso presentado por una asociación de empresarios contra la modificación de la ordenanza fiscal del citado municipio, que regulaba la tasa por utilización privativa o aprovechamiento especial del dominio público local.

El órgano a quo acogió parcialmente las pretensiones de la recurrente y anuló el artículo de la ordenanza relativo al cálculo de la tarifa de ocupación mediante la aplicación de un interés fijo sobre el valor del suelo. 
Frente a la sentencia de instancia, el municipio preparó el correspondiente recurso de casación, en el que se consideraba que se había vulnerado la doctrina del Tribunal Supremo sobre la cuestión controvertida. Por su parte, el TS admitió el recurso, precisando que la cuestión que presentaba interés casacional objetivo para la formación de jurisprudencia era reafirmar, aclarar o revisar la doctrina jurisprudencial propia sobre la posibilidad de utilizar el tipo de interés legal del dinero para determinar el valor de la utilidad derivada de la utilización privativa o del aprovechamiento especial del dominio público local, a efectos del art. 24.1.a) TRLRHL. En particular, se planteaba clarificar si, para que sea un criterio admitido en Derecho, es relevante que el porcentaje figure en el informe técnico-económico y no figure expresamente en la fórmula de cuantificación de la tasa contenida en la ordenanza fiscal.

A fin de resolver la cuestión, la Sala comienza recordando su doctrina en relación con la cuantificación de este tipo de tasas, que proscribe la utilización del tipo legal de interés del dinero, en tanto que se trata de un "parámetro fluctuante, movible, y, por tanto, susceptible de experimentar alteraciones todos los años, sin que bajo ninguna circunstancia ni vicisitud tales variaciones tengan aptitud para proyectarse sobre el quantum de la tasa que a tal criterio se remite» (FD 2. ${ }^{\circ}$ ).

Así pues, la Sala se remite a reiterar su doctrina ya establecida y, en cuanto al hecho de que el interés legal del dinero se encuentre en la memoria económico-financiera en vez de en el texto de la ordenanza, entiende que «lejos de solucionar el problema judicialmente constatado, lo agrava intensamente, pues al no aflorar a la ordenanza [...], el modo de cuantificación de ese componente de la cuota — la variable de ocupación - se sustrae al contribuyente, en la ordenanza misma, un elemento esencial de la formación de la tasa que debía ser conocido y ya no lo es» (FD 3. ${ }^{\circ}$ ).

En consecuencia, se declaró no haber lugar al recurso interpuesto por la citada entidad local, sin imponer las cosas procesales a ninguna de las partes.

Igualmente, se ha de dar cuenta de la STS de 12 de noviembre de 2020 (ECLI:ES:TS: 2020:3883), en la que se resolvió el recurso de casación preparado por el Ayuntamiento de Valencia contra la sentencia dictada en instancia por el Tribunal Superior de Justicia de la Comunidad Valenciana, en la que estimó parcialmente el recurso formulado por una mercantil contra la ordenanza fiscal reguladora de la tasa por utilización privativa o aprovechamiento especial del dominio público local de las instalaciones de transporte de energía eléctrica, gas, agua e hidrocarburos.

En la sentencia de instancia se anuló el artículo de la ordenanza fiscal relativo a la cuantificación, así como el anexo de tarifas, a causa de la falta de motivación suficiente en el informe técnico-económico. En particular, se afirmó que dicho informe no contenía una referencia explícita al módulo básico de repercusión (MBR) ni al módulo básico de construcción (MBC) que aplica.

Preparado el recurso, se estableció que la cuestión que presentaba interés casacional era matizar, precisar o, en su caso, revisar la jurisprudencia establecida, concretando si 
los informes técnico-económicos a los que se refiere el art. 25 TRLRHL pueden considerarse motivados cuando la determinación del MBR y del MBC se efectúan por remisión a la Orden EHA/3188/2006, de 11 de octubre, modificada por la Orden EHA/2816/2008, y a la ponencia de valores del municipio.

Por su parte, la Sala acoge los argumentos de la recurrente, afirmando que la normativa a la que se remite la ordenanza permite conocer los parámetros de cuantificación utilizados, de forma que fija como criterio interpretativo que, en orden a la cuantificación de una tasa de estas características, «debe considerarse motivado un informe técnico económico aunque este no contenga la expresión numérica del MBR y de los coeficientes empleados para la valoración del suelo con construcciones, porque estas cifras se pueden obtener acudiendo a la Orden EHA/3188/2006 y a la ponencia de valores del municipio» (FD 9.०).

En definitiva, se estimó el recurso de casación y no se impusieron las costas a ninguna de las partes. Debe advertirse que, en este mismo sentido, se han pronunciado las SSTS de 2 de diciembre de 2020 (ECLI:ES:TS:2020:4168), de 9 de diciembre de 2020 (ECLI:ES:TS:2020:4310), de 11 de diciembre de 2020 (ECLI:ES:TS:2020:4372) y de 17 de diciembre de 2020 (ECLI:ES:TS:2020:4335).

Asimismo, se ha de considerar la STS de 3 de diciembre de 2020 (ECLI:ES:TS:2020: 4162), en la que se resolvió el recurso de casación preparado por el Ayuntamiento de Rioseco de Tapia (León) contra la sentencia dictada en instancia por el Tribunal Superior de Justicia de Castilla y León, en la que se estimó parcialmente el recurso presentado por una mercantil contra la ordenanza fiscal del citado municipio, que regulaba la tasa por utilización privativa o aprovechamiento especial del dominio público local de las instalaciones de transporte de energía eléctrica, gas, agua e hidrocarburos.

El órgano a quo acogió parcialmente las pretensiones de la recurrente y anuló el artículo de la ordenanza relativo a la cuantificación de la tasa, así como el anexo de tarifas.

Por su parte, el TS admitió el recurso, precisando que existían dos cuestiones que presentaban interés casacional objetivo para la formación de jurisprudencia: por un lado, el cálculo del MBR y del MBC con remisión a la Orden EHA/3188/2006; y, por otro lado, concretar si en los supuestos de aprovechamiento especial de bienes del dominio público local es lícito imponer un tipo de gravamen del 5 por 100 sobre la base de la tasa que tomará, a su vez, como referencia, la utilidad que reporte el aprovechamiento.

En cuanto a la primera cuestión, la respuesta que da el TS es idéntica a la que se ha comentado en la sentencia anterior, a la que nos remitimos. En cuanto a la segunda, a pesar de que la Sala reconoce que en el art. 24.1 TRLRHL no existe una diferenciación expresa entre los supuestos de uso privativo o aprovechamiento especial, el precepto citado sí establece que el valor de mercado de la utilidad derivada se debe calcular «atendiendo a la naturaleza específica de la utilización privativa o del aprovechamiento especial de que se trate». En consecuencia, llega a la conclusión de que en los supuestos de aprovechamiento especial del dominio público no cabe imponer un tipo de gravamen 
del 5 por 100 sobre la base de la tasa que tomará, a su vez, como referencia, la utilidad que reporte el aprovechamiento cuando nos hallemos irrefutablemente ante un caso de aprovechamiento especial, no de uso privativo; y que la ordenanza fiscal, en los casos en que coincidan aprovechamiento especial y uso privativo, deberá justificar la intensidad o relevancia de cada uno de ellos a la hora de cuantificar la tasa.

En consecuencia, se declaró no haber lugar al recurso interpuesto por la citada entidad local, en lo que se refiere a la primera de las cuestiones, al tiempo que se declaró la nulidad de pleno derecho de la fijación de un tipo de gravamen único del 5 por 100, sin distinguir el tipo de aprovechamiento del demanio efectuado por el contribuyente. Debe advertirse que, en este mismo sentido, se han pronunciado las SSTS de 9 de diciembre de 2020 (ECLI:ES:TS:2020:4311), de 10 de diciembre de 2020 (ECLI:ES:TS:2020:4296), de 16 de diciembre de 2020 (ECLI:ES:TS:2020:4298) y de 17 de diciembre de 2020 (ECLI:ES:TS:2020:4402).

Por último, hay que referirse a la STS de 16 de diciembre de 2020 (ES:TS:2020:4370), en la que se analiza la particular fórmula de cuantificación de las tasas por utilización privativa o aprovechamiento especial del vuelo, suelo y subsuelo del dominio público local (comúnmente conocida como «tasa del 1,5 por 100»).

En este caso, el origen del pleito está en tres liquidaciones de la referida tasa giradas por el Ayuntamiento de Córdoba a Endesa, que fueron recurridas por la empresa eléctrica al entender que no se ajustaba a derecho la inclusión de las cuotas con destinos específicos en la base sobre la que se aplica el 1,5 por 100 .

Tanto en primera instancia como en apelación se desestimaron los recursos de la sociedad mercantil, remitiéndose a las consideraciones contenidas en la Sentencia del TSJ de Madrid, de 7 de abril de 2006 (ES:TSJM:2006:16293), en la Sentencia del TSJ de Galicia, de 24 de abril de 2013 (ES:TSJGAL:2013:4837) y en la Sentencia del TSJ de Valencia de 27 de noviembre de 2015 (ES:TSJCV:2015:5263), en la que se declara que los costes con destinos específicos no son equivalentes ni tienen la misma naturaleza que los ingresos específicos por cuenta de terceros, por lo que sí deben ser considerados a la hora de aplicar el 1,5 por 100 .

Sin embargo, el TS llega en esta sentencia a la conclusión contraria. Su razonamiento parte de la consideración de los denominados consumos específicos, que están regulados en el Real Decreto 2017/1997, de 26 de diciembre, por el que se organiza y regula el procedimiento de liquidación de los costes de transporte, distribución y comercialización a tarifa, de los costes permanentes del sistema y de los costes de diversificación y seguridad de abastecimiento. En particular, su art. 5 se ocupa de los costes definidos como cuotas con destinos específicos, estableciendo que los costes que se calcularán como cuotas específicas son:

- Los derechos de compensación por paralización de las centrales nucleares en moratoria referidos en la DA 7. a de la Ley 54/1997, de 27 de noviembre, del sector eléctrico. 
- Las cantidades destinadas a la financiación del segundo ciclo del combustible nuclear referidas en la disposición adicional sexta de la Ley 54/1997, de 27 de noviembre del sector eléctrico.

- Los costes del «stock» estratégico del combustible nuclear a que se refiere la disposición adicional decimotercera de la Ley 54/1997, de 27 de noviembre, del sector eléctrico.

- Los costes reconocidos al operador del sistema.

- Los costes reconocidos al operador del mercado.

- Los costes de funcionamiento de la Comisión Nacional del Sistema Eléctrico.

- Costes para las compensaciones específicas establecidas en el art. 4, párrafo i), del citado real decreto.

Teniendo presente que estas cantidades han de ser recaudadas por las empresas distribuidoras de electricidad, pero se destinarán a las finalidades que la ley indique, el TS entiende que no deben ser consideradas como ingresos propios de dichas empresas, sino como cantidades cobradas por cuenta de terceros.

En consecuencia, se declara haber lugar al recurso de casación y se fija como criterio interpretativo de la Sala con respecto a la cuestión con interés casacional que «las cuotas o costes con destinos específicos del Sistema Eléctrico Nacional deben ser excluidas en los ingresos brutos sobre los que aplicar el porcentaje del 1,5 por 100, a efectos del cálculo de la tasa por utilización privativa o aprovechamientos especiales constituidos en el suelo, subsuelo o vuelo de las vías públicas municipales, a favor de empresas explotadoras de servicios de suministros» (FD 3. ${ }^{\circ}$ in fine).

En cuanto a las novedades doctrinales referidas a esta materia, se han de reseñar los siguientes trabajos: O. DEL AMO GALÁN, «Sujetos pasivos de la tasa de carruajes», Carta tributaria, núm. 64, 2020; O. DEL AMO GALÁN, «Tributación local de la instalación de parques eólicos y huertos solares», Carta tributaria, núm. 62, 2020; y M. A. GARCíA CASTILLO, «La doble imposición - o no- por aprovechamiento especial del subsuelo y por el canon concesional del servicio municipal de aguas a la luz de la normativa de bienes de entidades locales de Andalucía", El Consultor de los Ayuntamientos y de los Juzgados, núm. 5, 2020.

\subsubsection{Tasas por la prestación de servicios o realización de actividades públicas}

En primer lugar, se ha de reseñar que, como ya se hizo el año pasado, abordaremos las novedades relativas a las prestaciones patrimoniales de carácter público no tributario en el epígrafe posterior "2. Otros ingresos», por tratarse de ingresos de naturaleza no tributaria.

En cuanto a las novedades jurisprudenciales relativas a las tasas por la prestación de servicios o realización de actividades públicas, cumple referirse a la STS de 8 de junio de 2020 (ECLI:ES:TS:2020:1527), que resolvió el recurso de casación interpuesto por el 
Ayuntamiento de Barcelona, contra la Sentencia del Tribunal Superior de Justicia de Cataluña, que estimó el recurso contencioso-administrativo presentado por una asociación frente al acuerdo del referido municipio de aprobación de una tasa por las actuaciones derivadas de la inspección y el control sobre las viviendas declaradas vacías o permanentemente desocupadas.

Preparado el recurso, la cuestión que presentaba interés casacional objetivo era determinar si «el Ayuntamiento de Barcelona es competente para aprobar disposiciones de carácter general en materia de control e inspección de las viviendas desocupadas y, en particular, si este servicio de inspección y control sobre las viviendas declaradas vacías o permanentemente desocupadas puede o no constituir el hecho imponible de la tasa litigiosa».

La Sala comienza recordando que solo puede estudiar y decidir reproches referidos a normas de Derecho estatal o de la Unión Europea, sin que en el recurso de casación se pueda controlar la interpretación que el órgano a quo ha realizado de las normas autonómicas. Así pues, lo que se revisa es la infracción del art. 20 TRLRHL apreciada en la instancia. Por su parte, el TS entiende — recordando su propia doctrina acerca de este tipo de tasas - que efectivamente se ha vulnerado el citado artículo porque la actuación que el municipio pretende gravar «no resulta encuadrable en ninguno de los servicios o actividades que se incluyen [en] el elenco de su apartado 4 y tampoco es de apreciar esa sustancial semejanza jurídica a que antes se ha hecho referencia» (FD 6.\%).

En virtud de lo anterior, la Sección entiende que procede la desestimación del recurso sin imponer las costas a ninguna de las partes. Adviértase que en este mismo sentido se han pronunciado las SSTS de 18 de junio de 2020 (ECLI:ES:TS:2020:1848) y de 8 de julio de 2020 (ECLI:ES:TS:2020:2248).

Asimismo, se ha de dar noticia de la STS de 15 de junio de 2020 (ECLI:ES:TS:2020: 1767), que resolvió los recursos de casación interpuestos por el Ayuntamiento de Almendralejo (Badajoz) y por una concesionaria contra la Sentencia del Tribunal Superior de Justicia de Extremadura, estimatoria del recurso interpuesto por un grupo municipal frente al acuerdo del pleno que modificó la tasa por el servicio de limpieza y extracción de acometidas, carteles y pintadas.

La cuestión que presentaba interés casacional era determinar si para la modificación de una ordenanza fiscal ya preexistente, reguladora de una tasa local por la prestación del servicio de abastecimiento de agua potable, dirigida a incrementar su importe mediante la aplicación del IPC —en los términos establecidos en el pliego que rige la contratación-, se requiere la elaboración de un informe técnico-económico o, por el contrario, se requiere la simple constatación, mediante un estudio, de que los costes del servicio han sufrido la inflación con respecto a los del año anterior.

A fin de resolver el recurso, la Sala comienza recordando que en la sentencia de instancia quedó acreditado que no se había justificado que el coste del servicio hubiese aumentado tanto como el IPC, lo que habría sido necesario para autorizar la subida. Así, 
siendo una cuestión probatoria la capital en la sentencia impugnada, entiende la Sala que debía haber sido inadmitido el recurso. En cualquier caso, teniendo presente que la anulación de la ordenanza se fundó en la valoración adversa de la prueba suscitada acerca del incremento de los costes del servicio, el TS declara no haber lugar a los recursos interpuestos, sin imposición de costas. Debe advertirse que en un sentido muy similar se han pronunciado las SSTS de 17 de junio de 2020 (ECLI:ES:TS:2020:1768), de 18 de junio de 2020 (ECLI:ES:TS:2020:1769) y de 18 de junio de 2020 (ECLI:ES:TS:2020:1770).

Igualmente, cumple referirse a la STS de 15 de octubre de 2020 (ECLI:ES:TS:2020: 3278) en la que se resolvió el recurso de casación presentado por el Ayuntamiento de Benquerencia de la Serena (Badajoz), contra la sentencia dictada por el Tribunal Superior de Justicia de Extremadura, que revocó, en apelación, la dictada por el Juzgado de lo Contencioso-Administrativo que desestimó el recurso frente a una liquidación de la tasa por licencia de obra girada a una mercantil.

Preparado el recurso por la citada entidad local, el interés casacional objetivo de la cuestión versaba en determinar si a efectos de la liquidación de una tasa de licencia urbanística (en particular de la determinación de su base imponible) resulta posible tener en consideración un acta con acuerdo posterior dictada por la Agencia Estatal de la Administración Tributaria en el seno de un procedimiento de comprobación de un tributo estatal como es el Impuesto sobre Sociedades.

Por su parte, el TS entiende que «ni las actas con acuerdo ni, en general, las valoraciones a efectos de otros tributos, vinculan a la Administración, salvo que: a) procedan de la misma Administración; $b$ ) aún a efectos de otros tributos y Administraciones, que lo que se esté valorando, física y jurídicamente, sea la misma cosa, a tenor de la regulación legal de cada figura tributaria, y c) que la valoración que se acepta e incorpora esté suficientemente motivada» (FD 3. ${ }^{\circ}$ ). Así pues, es improcedente la aplicación de los valores contenidos en un acta con acuerdo a la liquidación de la tasa controvertida.

En virtud de lo expuesto, se estimó el recurso, casando la sentencia de apelación y manteniendo la liquidación impugnada, sin imponer las costas a ninguna de las partes.

De igual modo, es también digna de mención la STS de 25 de noviembre de 2020 (ECLI:ES:TS:2020:3768) en la que se resuelve el recurso de casación preparado por una mercantil contra la sentencia dictada por el Tribunal Superior de Justicia de la Comunidad de Madrid, estimatoria del recurso de apelación interpuesto por el Ayuntamiento de Móstoles (Madrid) frente a la sentencia de instancia, que estimó el recurso de la mercantil contra varias liquidaciones de tasas por apertura de establecimientos, licencia de primera ocupación y alcantarillado, al entender que las ordenanzas municipales que regulaban las tasas reclamadas incurrían en incumplimientos legales que determinaban la nulidad de las liquidaciones.

Preparado el recurso de casación, se señaló que el interés casacional objetivo del pleito consiste en determinar si, con ocasión de la impugnación indirecta de una ordenanza fiscal, cabe alegar la falta de emisión de la memoria económico-financiera o 
su insuficiencia, al entenderse que se trata de un supuesto de incumplimiento de un requisito esencial en el procedimiento de elaboración de una disposición general, o, por el contrario, se considera que se trata de un mero vicio formal de dicho procedimiento y, como tal, no alegable en el recurso contencioso-administrativo indirecto.

Tras realizar un repaso de la evolución de su doctrina, el TS entiende que debe quedar fuera de la casación la valoración probatoria que, corrigiendo al juzgado, ha efectuado la sentencia de apelación para concluir que las magnitudes económicas consignadas en las ordenanzas reguladoras, a los efectos de acreditar la observancia del principio de equivalencia, sí están suficientemente justificadas en los informes técnico-económicos. Sin embargo, sostiene que sí merece ser estimada la vulneración del art. 24 TRLRHL en lo que se refiere a determinadas diferenciaciones que se realizan en la cuantificación, toda vez que no cumplen con «las pautas de razonabilidad y proporcionalidad» (FD 9. ${ }^{\circ}$ ).

Así pues, se estimó parcialmente el recurso, sin especial imposición de las costas.

En lo tocante a las novedades doctrinales acerca de la materia, cumple dar cuenta de la publicación de los siguientes trabajos: M. J. FERNÁNDEZ PAVÉS, «Tasas, prestaciones patrimoniales públicas y precios públicos», en P. J. CARRASCO PARRILla (dir.), Derecho tributario local y procedimientos tributarios, Atelier, Barcelona, 2020, pp. 51-102; C. MARTíneZ SÁnCHEZ, «Tasas y figuras análogas», en D. MARÍn-BARnUEVO FABO (dir.), La tributación local en esquemas, IDL-UAM, Madrid, 2020, pp. 151-170; C. MARTíNEZ SÁNCHEZ, Tasas locales y otras figuras afines, Ediciones Francis Lefebvre, Madrid, 2020; y E. SimÓn ACOSTA, «Tasas, tarifas y precios públicos», Quincena fiscal, núm. 14, 2020.

\subsection{Contribuciones especiales}

En lo que se refiere a los escasos pronunciamientos judiciales recaídos sobre esta materia, se ha de reseñar la STS de 11 de noviembre de 2020 (ECLI:ES:TS:2020:3722), que resolvió el recurso de casación interpuesto por un sindicato contra la Sentencia del Tribunal Superior de Justicia de Asturias, que desestimó el recurso presentado por ese mismo recurrente contra la sentencia dictada en primera instancia, que a su vez desestimó el recurso presentado contra una liquidación girada por el Ayuntamiento de Gijón (Asturias) en concepto de contribuciones especiales.

Preparado el recurso de casación, se señaló que el interés casacional objetivo del pleito consistía en determinar si, de la interpretación de los arts. 28, 29.3 y 30 TRLRHL, cabe inferir o no la exigencia de que el destino de las cantidades ingresadas por el concepto de contribuciones especiales sea exclusiva, íntegra e ineludiblemente para inversiones reales, o cabría también su aplicación al gasto corriente del servicio.

Tras realizar un repaso de la normativa que regula las contribuciones especiales, el TS entiende que «debido a su naturaleza, finalidad y a la manifestación de capacidad económica gravada, el importe de lo recaudado en concepto de contribuciones especiales, en caso de ampliación de servicios públicos preexistentes, como es en este caso el de 
extinción de incendios, ha de ser destinado necesariamente a los gastos de inversión de tal ampliación, de entre los previstos en el art. 33.1 [TRLRHL], sin que quepa su aplicación al funcionamiento ordinario del servicio» (FD 4. ${ }^{\circ}$ ). Acto seguido, especifica la Sala que no puede conceptuarse como discrecional la facultad de la Administración para destinar el importe de las contribuciones especiales a unos gastos u otros, pues solo es posible la aplicación a estrictos gastos de inversión.

Así pues, se estimó el recurso, si bien el TS entendió que solo procedía «declarar la nulidad de los actos presuntos en tanto no reconocen la improcedencia del reparto efectuado ni la aplicación a los fines previstos legalmente, no así en lo referido a la pretensión de condena, incompatible con los términos del art. 29.1 LJCA, amén de que las cantidades a que afecta la pretendida condena no han quedado acreditadas», sin imposición de costas.

Por otro lado, en lo que se refiere a las novedades doctrinales que se han publicado sobre la materia en 2020, cabe dar cuenta de los siguientes trabajos: F. FERNÁNDEZ MARÍN, «Las contribuciones especiales», en P. J. CARRASCO PARRILla (dir.), Derecho tributario local y procedimientos tributarios, Atelier, Barcelona, 2020, pp. 103-152; y C. MARTíNEZ SÁNCHEZ, «Las contribuciones especiales», en D. MARÍN-BARNUEVO FABO (dir.), La tributación local en esquemas, IDL-UAM, Madrid, 2020, pp. 171-184.

\section{Otros ingresos}

En lo referente a las novedades jurisprudenciales relativas a la materia, se ha de dar noticia de la STS de 23 de enero de 2020 (ECLI:ES:TC:2020:218), que resolvió los recursos de casación interpuestos por el Ayuntamiento de Alcudia (Baleares) y una concesionaria contra la Sentencia del Tribunal Superior de Justicia de las Islas Baleares, que estimó el recurso presentado por una asociación de empresarios contra la resolución de la Dirección General de Comercio y Empresa, que a su vez desestimó el recurso de reposición interpuesto contra la resolución de la Vicepresidencia económica, de promoción empresarial y ocupación que autorizaba las nuevas tarifas del servicio de suministro de agua potable.

Preparado el recurso de casación, se señaló que el interés casacional objetivo del pleito consistía en aclarar la doctrina jurisprudencial propia sobre el debate persistente en torno al art. 2.2.a) LGT, en su redacción posterior a la Ley de Economía Sostenible, relativo a la naturaleza jurídica de las cantidades cobradas a los usuarios del servicio de abastecimiento de agua potable prestado a través de formas indirectas y, en particular, a través de entidades concesionarias.

El objeto del pleito es idéntico al resuelto en la STS de 25 de junio de 2019 (ECLI:ES: TS:2019:2493), que ya analizamos en el Anuario de Derecho Municipal 2019. Así pues, la Sala reitera lo expresado en ella, donde se concluyó que, desde la supresión del segundo párrafo del art. 2.2.a) LGT, existe una opción discrecional para la Administración 
entre la configuración de la contraprestación como tasa o como precio y la opción por una modalidad de gestión directa o indirecta, si bien tal opción está limitada y legalmente predeterminada cuando el objeto de la actividad o servicio implica el ejercicio de autoridad.

En aplicación de la doctrina expuesta, se llegó a la conclusión de que se trataba de una "tarifa" y no de una tasa, como se había apreciado en la instancia, por lo que se estimó el recurso de casación ordenando la retroacción de las actuaciones al momento procedimental anterior a dictar sentencia, sin especial imposición de costas a ninguna de las partes. En un sentido análogo se pronunciaron las dos SSTS de 28 de enero de 2020 (ECLI:ES:TS:2020:136 y ES:TS:2020:229, respectivamente).

Igualmente, se ha de abordar la STS de 23 de junio de 2020 (ECLI:ES:TC:2020:1839), que resolvió el recurso de casación interpuesto por el Ayuntamiento de Madrid (Madrid) contra la Sentencia del Tribunal Superior de Justicia de Madrid, que estimó el recurso presentado por una concesionaria de un centro deportivo y casa de baños contra el acuerdo plenario de modificación de los precios públicos por la prestación de servicios en centros deportivos y casas de baños.

Preparado el recurso de casación, se señaló que el interés casacional objetivo del pleito consistía en dilucidar si, para aquellos servicios prestados en centros deportivos y casas de baños de gestión indirecta, la reducción de la cuantía de los precios públicos satisfechos por los usuarios debe ir acompañada, en cumplimiento de los arts. 26.2 LTPP y 44 TRLRHL, de un informe técnico-económico que justifique el importe reducido de los mismos y el grado de cobertura de los costes correspondientes.

Tras realizar un repaso de la evolución de la normativa y la jurisprudencia en relación a la naturaleza jurídica de las contraprestaciones exigidas por el uso de los servicios públicos, la Sala concluye que, puesto que el servicio es de solicitud voluntaria y se presta por medio de un concesionario, se ha de concluir que la contraprestación no es un precio público, sino un precio privado.

En aplicación de lo anterior, el TS decidió estimar el recurso de casación, desestimando el recurso contencioso-administrativo interpuesto frente al acuerdo plenario, si bien no se dio respuesta a la cuestión que justificó el interés casacional del pleito, en tanto que, a su juicio, parte de un presupuesto inexistente, toda vez que lo que percibe el concesionario no puede ser calificado como precio público. Asimismo, no se impusieron las costas a ninguna de las partes. Adviértase que en un sentido análogo se pronunciaron las SSTS de 24 de junio de 2020 (ECLI:ES:TS:2020:2218) y de 7 de octubre de 2020 (ECLI:ES:TS:2020:3299).

Por último, en cuanto a las novedades doctrinales sobre la materia se han de referir los siguientes trabajos: O. DEL AMO GALÁN, «Prestaciones patrimoniales de carácter público y jurisprudencia del Tribunal Supremo», Carta tributaria, núm. 69, 2020; I. JIMÉNEZ COMPAIRED, «La competencia jurisdiccional en relación con el cobro de las prestaciones patrimoniales de carácter público no tributarias», Revista española de derecho 
financiero, Civitas, núm. 187, 2020, pp. 85-130; D. ORTIZ ESPEJO, «Algunas reflexiones sobre la nueva categoría "prestaciones patrimoniales públicas no tributarios" introducida por la Ley 9/2017, de 8 de noviembre, de Contratos del Sector Público", Tributos Locales, núm. 146, 2020, pp. 103-121; y M. A. VALENZUELA VILLARRUBiA, «La financiación de los servicios públicos locales mediante prestaciones patrimoniales de carácter público no tributario», El Consultor de los Ayuntamientos y de los Juzgados, núm. 11, 2020.

\section{PROCEDIMIENTOS TRIBUTARIOS EN EL ÁMBITO LOCAL}

Durante el ejercicio 2020, no ha habido modificaciones significativas en relación con los procedimientos tributarios. Sin embargo, ha tenido especial repercusión la declaración del primer estado de alarma como consecuencia de la crisis sanitaria provocada por la covid-19. En este sentido, fueron muchos los ayuntamientos que adoptaron medidas tributarias, como la suspensión del pago de los tributos. A nivel general, debemos destacar las previsiones relativas a la suspensión de plazos, prescripción y caducidad de los procedimientos tributarios entre el 14 de marzo y el 30 de mayo de 2020, por aplicación del art.33 del Real Decreto-ley 8/2020, de 17 de marzo de medidas urgentes extraordinarias para hacer frente al impacto económico y social de la covid-19 y el art. 53 y la Disposición adicional novena del Real Decreto-ley 11/2020, de 31 de marzo, por el que se adoptan medidas urgentes complementarias en el ámbito social y económico para hacer frente a la covid-19. Además, como consecuencia de dicha crisis sanitaria, algunos ayuntamientos se plantearon la posibilidad de establecer bonificaciones respecto de los tributos locales del ejercicio 2020. A este respecto, podemos citar los trabajos de Ó. DEL AMO GALÁN, «Adecuación de los tributos locales a la situación económica derivada de la pandemia», Carta tributaria, núm. 68, 2020; «Impuesto sobre bienes inmuebles (IBI). Es necesario que una norma con rango de ley prevea y habilite que una Ordenanza fiscal tenga efectos retroactivos", El Consultor de los Ayuntamientos y de los Juzgados, núm. 7, 2020; y «Impuesto sobre el Incremento de Terrenos de Naturaleza Urbana (IIVTNU). Las bonificaciones en el impuesto de plusvalía no podrán tener efectos retroactivos», $E l$ Consultor de los Ayuntamientos y de los Juzgados, núm. 5, 2020.

En el plano catastral, la Disposición final décima octava de la Ley 11/2020, de 30 de diciembre, de Presupuestos Generales del Estado para el año 2021, modifica la Disposición transitoria segunda del TRLCI relativa a la valoración catastral de los bienes inmuebles rústicos. Además, respecto de la remisión de información, debemos mencionar la Resolución de 23 de septiembre de 2020, de la Subsecretaría de la Presidencia, Relaciones con las Cortes y Memoria Democrática, por la que se publica el Convenio entre la Agencia Estatal de Administración Tributaria y el Instituto Nacional de Estadistica, en materia de intercambio de información para fines estadísticos y tributarios, y la Resolución de 7 de octubre de 2020, de la Subsecretaría de la Presidencia, Relaciones con las Cortes y Memoria Democrática, por la que se publica la Resolución conjunta de la Dirección General de Seguridad Jurídica y Fe Pública y de la Dirección General del Catastro, por la que se aprueban especificaciones 
técnicas complementarias para la representación gráfica de las fincas sobre la cartografia catastral y otros requisitos para el intercambio de información entre el Catastro y el Registro de la Propiedad. Asimismo, también debemos citar la Resolución de 10 de septiembre de 2020, de la Dirección General del Catastro, por la que se aprueba el documento normalizado de representación en los procedimientos tributarios. Adicionalmente, en el ejercicio 2020 se ha publicado la suscripción de cerca de 70 convenios de colaboración entre la Dirección General del Catastro y algunas entidades locales u otras administraciones e instituciones, así como la extinción de 43 convenios.

La gestión catastral ha sido una temática bastante tratada durante el año 2020. En el plano jurisprudencial, la STS de 28 de mayo de 2020 (ECLI:ES:TS:2020:1440) argumenta que el procedimiento de subsanación de discrepancias regulado en el art. 18 del TRLCI únicamente tiene efectos hacia al futuro. Por su parte, la STS de Madrid de 20 de julio de 2020 (ECLI:ES:TSJM:2020:9225) estima que los errores fácticos producidos en el Catastro Inmobiliario deben corregirse mediante un procedimiento de corrección de errores del art. 220 de la LGT y, en consecuencia, los efectos beneficiosos para el contribuyente deben retrotraerse al momento en el que se produjeron. La STS de 3 de junio de 2020 (ECLI:ES:TS:2020:1752) concluye que el valor catastral resultante de un procedimiento de subsanación de discrepancias conlleva la correspondiente devolución de las cuantías abonadas en exceso, mediante el procedimiento de devolución de ingresos indebidos (art. 221 de la LGT). Respecto de la recaudación de este impuesto, destaca el trabajo de B. MORENO SERRANO, «La afección del inmueble al pago del IBI», El Consultor de los Ayuntamientos y de los Juzgados, núm. extra 4, 2020, pp. 131-139.

Por otro lado, la STSJ de Galicia de 27 de enero de 2020 (ECLI:ES:TSJGAL:2020:37) entiende que las casas prefabricadas («mobil home») deben recibir la consideración de inmueble a efectos del art. 7 del TRLCI, pues cuentan con los servicios y los suministros relativos a una vivienda. En el supuesto de los BICES, la STSJ de Castilla y León (sede en Burgos) de 10 de febrero de 2020 (ECLI:ES:TSJCL:2020:667) analiza la valoración catastral de una central nuclear que ha cesado definitivamente su actividad por denegarse la renovación de la autorización de explotación. En consecuencia, el titular catastral realiza la consiguiente declaración, pero la sentencia argumenta que, hasta que no se produzca la modificación del valor catastral y/o su eficacia, el Ayuntamiento debe emitir la correspondiente liquidación del IBI. En el plano administrativo, la RTEAC de 25 de junio de 2020 ( $R G$ 6801/2017) estima que una solicitud de rectificación de errores no puede tramitarse como procedimiento de declaración catastral. Asimismo, el ATS de 9 de octubre de 2020 (ECLI:ES:TS:2020:8572A) admite un recurso de casación en el que deberá pronunciarse sobre si la motivación de la fijación de un determinado valor catastral debe incorporarse en la ponencia de valores o, en su caso, en el acto de asignación individual del citado valor.

Diversos autores han estudiado aspectos interesantes que analizan la gestión catastral y sus relaciones con los ayuntamientos. Así, debemos citar los trabajos de R. PÉREz SÁEZ, «Gestión catastral y gestión tributaria del IBI. Principio de buena administración», $L a$ 
administración práctica, núm. 7, 2020, pp. 151-155; A. I. MATEO LOZANO, «El valor catastral al servicio del IBI y de las Haciendas Locales», El Consultor de los Ayuntamientos y de los Juzgados, núm. extra 4, 2020, pp. 39-49, y F. DE ARAGÓN AMUNÁRRIZ, «La colaboración del Catastro con las Entidades Locales», El Consultor de los Ayuntamientos y de los Juzgados, núm. extra 4, 2020, pp. 23-38. Además, también hay trabajos que estudian el funcionamiento del Catastro Inmobiliario, como son M. A. GARCÍA VALDERREY, «Sobre el procedimiento para la renovación de las Juntas Periciales Municipales del Catastro», El Consultor de los Ayuntamientos y de los Juzgados, núm. 9, 2020; y B. MORENO SERRANO, «Procedimiento de subsanación de discrepancias en el catastro inmobiliario», El Consultor de los Ayuntamientos y de los Juzgados, núm. 7, 2020. Por último, también hay autores que han estudiado la coordinación entre el Catastro y el Registro de la Propiedad, como, por ejemplo, E. BRANCÓS I NúNEEZ, «La presunción de exactitud aplicada a la coordinación Catastro-Registro", El notario del siglo XXI: revista del Colegio Notarial de Madrid, núm. 89, 2020, pp. 72-77; y J. CALVO VÉRGEZ, «La necesaria armonización de la legislación hipotecaria y del Catastro inmobiliario. Reflexiones en torno a los avances alcanzados», Revista Aranzadi Doctrinal, núm. 10, 2020.

Otro aspecto que ha resuelto el TS en su sentencia de 18 de mayo de 2020 (ECLI:ES: TS:2020:980) ha sido el relativo al ejercicio de competencias recaudatorias y gestoras en el marco de la delegación de competencias mediante convenio con la Comunidad Autónoma en el sentido de determinar si la facultad para dictar providencias de apremio le corresponde a la Administración delegante o a la delegada. En esta sentencia, el TS ha resuelto que «para la determinación del órgano competente para dictar providencias de apremio ha de estarse a los término del Convenio con la Comunidad Autónoma sobre la delegación de funciones de gestión y recaudación de tributos y otros ingresos municipales, en tanto que en el mismo debe plasmarse el marco competencial que se traspasa, que en definitiva determina el órgano u organismo responsable de dictar los actos administrativos de los que se han de derivar los efectos jurídicos propios de la concreta actividad material».

Por otro lado, respecto del procedimiento impugnatorio del IIVTNU, la STS 6 de marzo de 2020 (ECLI:ES:TS:2020:722) ha cerrado la puerta a la posibilidad de instar un procedimiento de revisión de nulidad de pleno derecho de las liquidaciones firmes del IIVTNU, en base a las declaraciones de inconstitucionalidad de su normativa reguladora. De forma similar, también se ha pronunciado la STSJ de Navarra de 26 de mayo de 2020 (ECLI:ES:TSJNA:2020:106). En la misma línea, la STS de 18 de mayo de 2020 (ECLI:ES:TS:2020:970) estima que no es posible solicitar la devolución de una liquidación de IIVTNU firme. Estos procedimientos judiciales han sido objeto de análisis en los trabajos de V. A. GARCía Moreno, "Derecho a la devolución de ingresos o derecho a instar la devolución: el impuesto sobre el Incremento del Valor de los Terrenos de Naturaleza Urbana y las liquidaciones firmes: Sentencia del Tribunal Supremo núm. 333/2020, de 6 de marzo de 2020», Carta tributaria, núm. 62, 2020; B. Moreno Serrano, «El Tribunal Supremo se pronuncia en relación con la revisión de liquidaciones firmes del IIVTNU», El Consultor de los Ayuntamientos y de los Juzga- 
dos, núm. 5, 2020; B. GÓRRIz GÓMEZ, «IIVTNU: las liquidaciones tributarias firmes que vulneren el art. 31.1 de la Constitución no son nulas de pleno derecho", Actualidad administrativa, núm. 11, 2020; I. SuberbIOla GarbIZU, «El gato de Schrödinger tributario o la paradoja del IIVTNU: sobre la delimitación de los efectos de la declaración de inconstitucionalidad del Impuesto y la nulidad de sus liquidaciones firmes. Análisis de la STSJN de 26 de mayo de 2020", Nueva fiscalidad, núm. 3, 2020, pp. 255-266; V. A. GarCía Moreno, «La vulneración del Derecho comunitario sí que puede ser causa de nulidad de liquidaciones consentidas y firmes: Sentencias del Tribunal Supremo núms. 1.016/2020 y 1.015/2020, de 16 de julio, Sala Tercera, de lo Contencioso-Administrativo (rec. 810/2019 y 4334/2017, respectivamente)», Carta tributaria, núm. 68, 2020; y V. A. GarCía Moreno, "Menos devoluciones del Impuesto sobre Plusvalías declarado inconstitucional: Sentencia del Tribunal Supremo de 18 de mayo de 2020, núm. 436/2020», Carta tributaria, núm. 65-66, 2020.

Además, no debemos olvidar algunas controversias que se han planteado este año y de las que deberá conocer el Tribunal Supremo. En concreto, el ATS de 29 de octubre de 2020 (ECLI:ES:TS:2020:10058A) debe analizar si, en base del art. 44 de la Ley 29/1998, de 13 de julio, reguladora de la Jurisdicción Contencioso-Administrativa, una Administración puede formular un requerimiento a otra solicitando el cese de un procedimiento de ejecución cuando es destinataria de una providencia de apremio dictada en base a una ordenanza fiscal que ha sido anulada judicialmente. Por su parte, el ATS de 22 de octubre de 2020 (ECLI:ES:TS:2020:9481A) plantea si puede dictarse una providencia de apremio contra un ayuntamiento para, posteriormente, acordar la compensación de oficio.

Finalmente, hay que citar diversas aportaciones doctrinales en relación con los procedimientos tributarios en el ámbito local. En concreto, hay que mencionar los trabajos de F. J. GARCÍA VERA, «La suspensión sin garantías y el recurso de reposición en la esfera tributaria local», Tributos locales, núm. 145, 2020, pp. 71-91; M. M. MARTíneZ MoRANT, «Los desafíos de los obligados y las Administraciones tributarias ante las consultas tributarias en el ámbito local», Estudios financieros. Revista de contabilidad y tributación, núm. 447, 2020, pp. 55-86; J. D. CORDERO GONZÁlEZ, "Particularidades locales en los procedimientos de Revisión tributaria en vía administrativa: especial atención a la Suspensión», Tributos locales, núm. 144, 2020, pp. 111-128; R. Oliver Cuello, "Los procedimientos de revisión en los tributos locales», en P. J. CARrasco PARRILLA (dir.), Derecho tributario local y procedimientos tributarios, 2020, pp. 485-501; J. A. MONTERO FERNÁNDEZ, «Recurso de casación: sentencias dictadas y pendientes», El Consultor de los Ayuntamientos y de los Juzgados, núm. extra 4, pp. 140-154; A. BERGAS FORTEZA, «Sobre la incompatibilidad establecida en el arte 107 TFUE en las exenciones fiscales.: Comentarios a la Sentencia del TJUE de 27 de junio de 2017 y su aplicación actual», Tributos locales, núm. 146, 2020, pp. 89-102; Ó. DEL AMO GALÁN, "Beneficios fiscales en los tributos locales. Posibilidad de conceder subvenciones para compensar o minorar el pago de los tributos», Carta tributaria, núm. 60, 2020; A. VAQUERA GARCía, "Establecimiento y ordenación de los tributos locales», en P. J. Carrasco Parrilla (dir.), Derecho tributario local y procedimientos tributarios, 2020, pp. 19-50; R. OLIVER 
Cuello, «Las infracciones y sanciones en los tributos locales», en P. J. CARrasco PARRILLA (dir.), Derecho tributario local y procedimientos tributarios, 2020, pp. 485-501; B. Moreno SERRANO, "Legitimación para recurrir tributos locales», La administración práctica, núm. 2, 2020, pp. 49-62; N. TEIXIDOR MARTínEZ, «Los sujetos obligados al pago de un tributo local por contrato se hallan legitimados para proceder a su impugnación (Análisis de la STS de 30 de octubre de 2019, rec. núm. 3.738/2018)», Estudios financieros. Revista de contabilidad y tributación, núm. 443, 2020, pp. 144-152; Ó. DEL AMO GALÁN, «Tributación local de la instalación de parques eólicos y huertos solares», Carta tributaria, núm. 62, 2020; y D. MARÍN-BARNUEVO FABO (dir.), La tributación local en esquemas, Universidad Autónoma de Madrid, Instituto de Derecho Local, 2020. 
